\title{
HIGH TEMPERATURE MICROSTRUCTURAL DEGRADATION OF HAYNES ALLOY 230
}

\author{
J.Veverkova $^{1}$, A.Strang ${ }^{1}$, G.R.Marchant ${ }^{2}$, G.M.McColvin ${ }^{3}$ and H.V.Atkinson ${ }^{1}$ \\ ${ }^{1}$ Department of Engineering, University Road, University of Leicester, Leicester, LE1 7RH, UK \\ ${ }^{2}$ Siemens Industrial Turbomachinery Ltd., Ruston House, Lincoln LN5 7FD, UK \\ ${ }^{3}$ Formerly at Siemens Industrial Turbomachinery Ltd., Lincoln, UK
}

Keywords - HA230, microstructural evolution, thermal and creep exposure, hardness, FEGSEM, EDX and XRD

\begin{abstract}
Haynes Alloy $230^{\mathrm{TM}}$ is a solid solution strengthened nickelbased material used for combustion components in industrial gas turbines. In this application a primary limit to the component design life is the response of the material to high temperature exposure with and without mechanical loading. Over long periods of operation in service, this leads to degradation of the microstructure of the alloy and consequently to its mechanical properties. A detailed understanding of the processes associated with in-service the microstructural degradation of the alloy and its effects on the mechanical properties of the material is therefore of great importance in the drive for increased component life and reliable extended plant operation.
\end{abstract}

In order to investigate the effects of thermal and long-term creep exposure on the degradation behaviour of Haynes Alloy 230 sheet material during service, detailed studies of the microstructural changes taking place in this material have been made using advanced analytical FEGSEM, EDX and XRD techniques. The objective of the programme is to quantify the microstructural changes and phase precipitation reactions occurring as a result of service exposure, based upon the use of laboratory controlled thermally aged and creep tested samples.

Haynes Alloy 230 was specifically designed to have excellent long-term thermal stability and resistance to the precipitation of damaging phases. However, whilst this appears to be true for unstressed thermal exposure, there is growing evidence from the studies to date that, in addition to the primary $\mathrm{M}_{6} \mathrm{C}$ and the precipitation of $\mathrm{M}_{23} \mathrm{C}_{6}$ resulting from thermal exposure, other phases can precipitate in the alloy, under the influence of timedependent plastic deformation during long-term creep exposure, which can lead to reductions in both ductility and high temperature strength.

This paper describes some detailed studies on the effects of long-term high temperature exposure on the hardness and microstructural changes in creep rupture tested and thermally exposed samples of Haynes Alloy 230.

\section{Introduction}

Modern industrial gas turbines are expected to have an operational life expectancy of 100,000 hours or more depending on the applications and duty cycles for which they have been designed. In addition, they are also expected to have high thermal efficiencies, a high degree of reliability as well as a minimum of outages for routine maintenance. Furthermore, in order to satisfy today's requirements to minimise their environmental impact, plant operators and utilities are continually seeking further improvements in thermal efficiencies, reduced emissions, operating and maintenance costs, in combination with increases in plant design life. This means that there is a continual demand for turbine builders to meet these aims by extending the lives of critical turbine components operating at present temperatures and stresses through design modifications and/or making use of higher strength materials, as well as for alloy producers to develop methods of improving the high temperature properties of currently available alloys or to research new alloy development. One critical area in which these demands have a direct impact on gas turbine design and performance is the choice of suitable alloys for high temperature gas path components such as combustion cans and transition ducts. For these applications alloys are required to have a combination of high temperature creep and thermo-mechanical fatigue strength, coupled with long-term thermal stability and corrosion resistance in oxidising and nitriding environments at service temperatures up to $1150^{\circ} \mathrm{C}$, together with good formability and weldability characteristics. In addition there is a requirement for the design life of these components to be greater than the normal planned operational engine service period of $\sim 30,000$ hours.

Haynes Alloy $230^{\mathrm{TM}}$, originally developed in the 1980 's for aerospace, power plant and chemical processing industries applications, was designed to satisfy these requirements and as such was selected as a suitable material for the manufacture of sheet metal combustion hardware for Siemens industrial gas turbines with outputs up to $14 \mathrm{MW}$. This solid solution strengthened nickel based alloy was originally developed from the Ni-Cr-Mo-W system in which the high nickel content provides a stable austenitic matrix with chromium, tungsten, molybdenum, carbon and boron additions, providing the alloy's high temperature strength and corrosion resistance [1]. Effective solid solution strengthening is achieved through high tungsten content with carbon promoting the formation of chromium rich $\mathrm{M}_{23} \mathrm{C}_{6}$ carbides, which precipitate on the primary austenite and annealing twin boundaries, pinning dislocations and thereby contributing to the alloy's creep strength. These, together with the presence of tungsten rich primary $\mathrm{M}_{6} \mathrm{C}$ precipitates in the matrix provide resistance to grain coarsening during prolonged exposure at high service temperatures. Tungsten was also specifically chosen in preference to molybdenum as a major alloying element, since it diffuses more slowly in nickel as well as increasing the elastic moduli and decreasing the stacking fault energy hence impeding cross-slip, all of which promote high-temperature creep and fatigue strength. Finally, improved resistance to surface attack in oxidising and nitriding environments is provided by the additions of chromium, manganese, silicon and lanthanum, with the latter element contributing to the stabilisation of the surface protective chromia scale generated during service exposure [2-5].

Wrought product forms of HA230, e.g., bar, plate or sheet, are normally produced by rolling an electro-slag re-melted ingot on 
a reversing mill at a temperature of approximately $1200^{\circ} \mathrm{C}$. Thinner gauge sheet products may be finished by cold rolling prior to final annealing. After rolling to the final product size the material is solution annealed within the temperature range $1177^{\circ} \mathrm{C}$ to $1246^{\circ} \mathrm{C}$ and rapidly cooled or water quenched. This results in an equiaxed microstructure with an average grain size in the range of ASTM 4-6. In this annealed condition, tungstenrich primary $\mathrm{M}_{6} \mathrm{C}$ carbides are present at grain boundaries as well as dispersed throughout the microstructure in the form of stringers. These resist re-solution during the annealing treatment of the material thus enabling a controlled grain size range to be achieved. This results in an optimum combination of high temperature creep rupture and thermo-mechanical fatigue (TMF) properties. In addition to the primary $\mathrm{M}_{6} \mathrm{C}$ precipitates present in the annealed condition some chromium rich $\mathrm{M}_{23} \mathrm{C}_{6}$ may also be present precipitated at the grain boundaries and on annealing twins within the microstructure, Figure 1 [2-4].

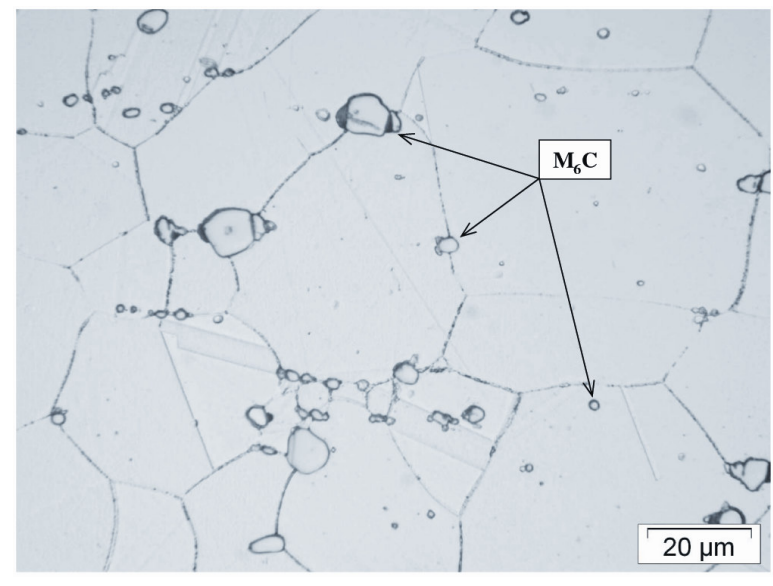

Figure 1. Microstructure of annealed and quenched HA230 showing primary $\mathrm{M}_{6} \mathrm{C}$ particles.

In industrial gas turbines components, such as combustion cans and transition ducts, manufactured from the alloy are exposed for prolonged periods of time at high temperatures and experience complex thermal cycles which vary according to operational requirements and planned life expectancy for the plant. The combined effects of high temperature thermal exposure and plastic deformation in the material, due to creep and thermo-mechanical fatigue during service, result in microstructural changes which significantly affect the alloy mechanical properties and in consequence life-limit key turbine components. In practice these microstructural changes can include precipitation of secondary phases, such as carbides and possibly intermetallic compounds, as well as recovery and recrystallisation effects. The primary objectives of this investigation are therefore to establish an understanding of these processes and their effects on the microstructural stability and mechanical properties of HA230, and quantify the parameters affecting the service performance and design life of gas turbine combustion hardware manufactured from this alloy.

In order to achieve this, the microstructures of samples of the alloy exposed for durations of up to 20,000 hours at temperatures in the range $600^{\circ} \mathrm{C}$ to $1050^{\circ} \mathrm{C}$ have been compared with that exhibited by the alloy in its original solution annealed condition. Microstructural changes observed in material taken from the same heat of this alloy which had been creep rupture tested at temperatures between $600^{\circ} \mathrm{C}$ to $1000^{\circ} \mathrm{C}$ for durations of up to 50,000 hours have also been compared with those found in the unstressed as-received and thermally aged samples. This paper describes the work carried out in the first phase of the project and includes hardness as well as optical, FEGSEM and XRD studies on thermally exposed and creep tested HA230.

\section{Materials}

Both the thermal exposure and creep rupture tests were carried out on specimens taken from a $2 \mathrm{~mm}$ thick sheet of HA230 supplied by Haynes International Ltd, which had been solution annealed at $1230^{\circ} \mathrm{C}$ and quenched in accordance with AMS 5878. The chemical composition of this heat, together with the AMS 5878 specification requirements are shown in Table I.

\section{Results and Discussion}

\section{Hardness Studies}

Thermal exposure tests. The results of Vickers hardness measurements on sections taken from unstressed coupons of HA230 exposed for durations of up to 20,000 hours at temperatures in the range $600^{\circ} \mathrm{C}$ to $1050^{\circ} \mathrm{C}$ are shown in Figures $2 \mathrm{a}$ and $\mathrm{b}$. In each case the values plotted are the average of at least twenty hardness impressions made using a $20 \mathrm{~kg}$ load. The results obtained indicate that systematic changes in hardness occur in the alloy with increasing exposure durations at all of the test temperatures investigated.

Examination of the 1000 hours exposure results indicate that for temperatures in the range $600^{\circ} \mathrm{C}$ to $870^{\circ} \mathrm{C}$ the hardnesses increases from an average value of $217.8 \mathrm{Hv} 20$ in the original solution annealed condition, reaching maximum values of 250.4 $\mathrm{Hv} 20$ and $226.5 \mathrm{Hv} 20$ respectively after exposure at $650^{\circ} \mathrm{C}$ and $870^{\circ} \mathrm{C}$, i.e. an increase of $15 \%$ and $4 \%$ compared with the material in the original solution annealed condition. For temperatures greater than $870^{\circ} \mathrm{C}$ exposure for 1000 hours resulted in softening of the alloy, by approximately $1 \%$ at $930^{\circ} \mathrm{C}$ and $3 \%$ at $1050^{\circ} \mathrm{C}$.

The 1000 hours exposure data shown in Figure $2 b$ also indicates that following initial hardening, re-softening of the alloy occurs with increasing exposure temperature, with the original hardness level being regained at a temperature of approximately $925^{\circ} \mathrm{C}$. Above this further softening occurs with the curve reaching a minimum of $\sim 210 \mathrm{Hv} 20$ at about $990^{\circ} \mathrm{C}$, before

Table I. Test Certificate Chemical Analysis (wt\%) of HA230 Heat No 8305-5-7170

\begin{tabular}{|c|c|c|c|c|c|c|c|c|c|c|c|c|}
\hline Heat No & $\mathrm{Ni}$ & $\mathrm{Cr}$ & $\mathrm{W}$ & Mo & $\mathrm{Fe}$ & Co & $\mathrm{Mn}$ & $\mathrm{Si}$ & $\mathrm{Al}$ & $\mathrm{C}$ & $\mathrm{La}$ & B \\
\hline $8305-5-7170$ & Bal & 21.75 & 13.96 & 1.32 & 1.40 & 0.37 & 0.49 & 0.36 & 0.29 & 0.12 & 0.013 & 0.004 \\
\hline AMS 5878 & $\mathrm{Bal}$ & $\begin{array}{c}20.0 \\
\text { to } \\
24.0\end{array}$ & $\begin{array}{c}13.00 \\
\text { to } \\
15.00\end{array}$ & $\begin{array}{c}1.00 \\
\text { to } \\
3.00\end{array}$ & $\begin{array}{l}3.00 \\
\max \end{array}$ & $\begin{array}{l}5.00 \\
\max \end{array}$ & $\begin{array}{c}0.30 \\
\text { to } \\
1.00\end{array}$ & $\begin{array}{c}0.25 \\
\text { to } \\
0.75\end{array}$ & $\begin{array}{c}0.20 \\
\text { to } \\
0.50\end{array}$ & $\begin{array}{c}0.05 \\
\text { to } \\
0.15\end{array}$ & $\begin{array}{c}0.005 \\
\text { to } \\
0.05\end{array}$ & $\begin{array}{c}0.015 \\
\max \end{array}$ \\
\hline
\end{tabular}



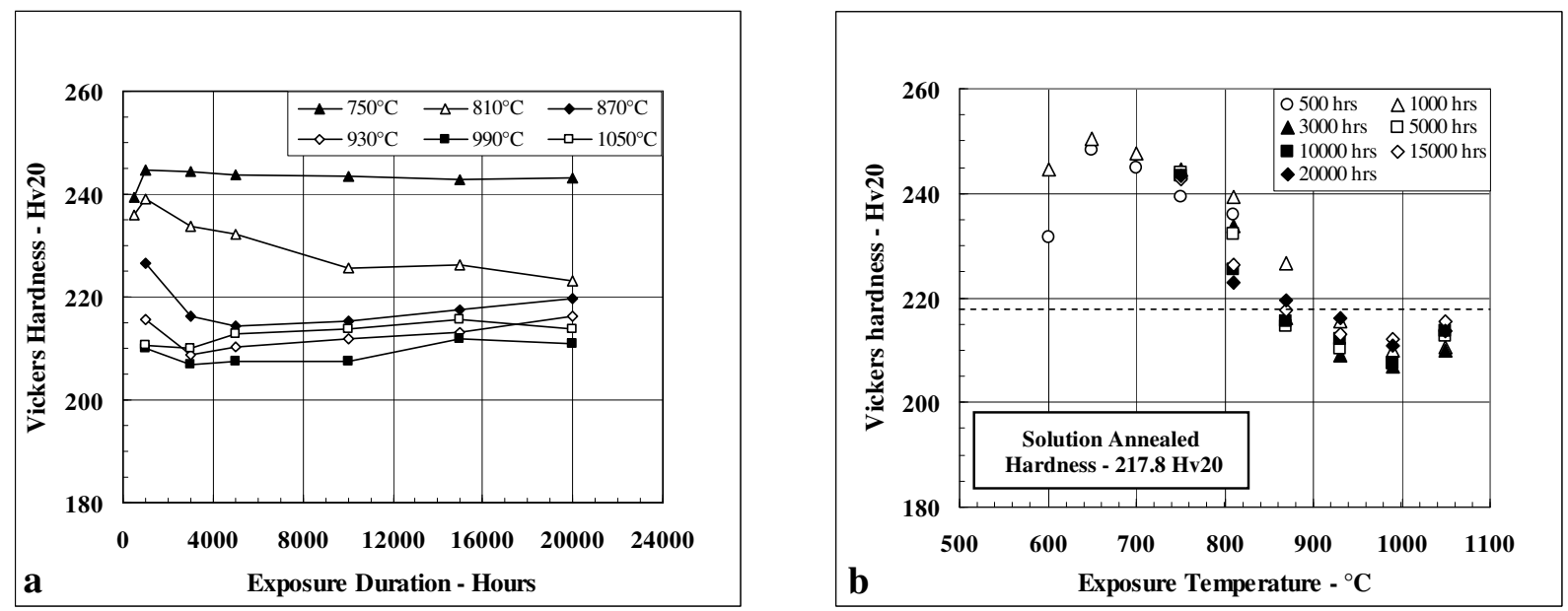

Figures $2 \mathrm{a}$ and $2 \mathrm{~b}$. Hardness changes in HA230 with increasing exposure durations and temperatures.

increasing once more at $1050^{\circ} \mathrm{C}$. Similar patterns of behaviour are observed for longer exposure durations with the data for 3 , $5,10,15$ and 20 thousand hours following a similar trend. The data shown in Figure 2b also suggests that in the unstressed condition the maximum degree of thermal hardening is observed between $600^{\circ} \mathrm{C}$ and $700^{\circ} \mathrm{C}$ with the maximum softening temperature for the alloy occurring close to $1000^{\circ} \mathrm{C}$.

Analysis of thermal exposure hardness data. The hardness data for the unstressed thermally exposed coupons of HA230 can conveniently be plotted as a function of the Larson-Miller timetemperature parameter $\mathrm{P}$, derived from the Arrhenius equation and expressed as,

$$
\mathrm{P}=\mathrm{T}(\mathrm{C}+\log \mathrm{t}) / 1000
$$

where, $\mathrm{T}$ is the exposure temperature in Kelvin, $\mathrm{t}$ is the exposure duration in hours and $\mathrm{C}$ is the Larson-Miller constant.

Adopting a value of 20 for the constant $\mathrm{C}$ results in the LarsonMiller parametric plot for the hardness data obtained on the thermally exposed HA230 alloy shown in Figure 3. From this plot it can be seen that the maximum and minimum measured hardness values of $250.4 \mathrm{Hv} 20$ and $207.4 \mathrm{Hv} 20$ correspond respectively to Larson-Miller Parameter values of approximately 21 and 30 .

A least squares regression analyses of this hardness data set shown in Figure 3 against the Larson-Miller parameter $P$ indicates that a good fit is obtained using a third order polynomial of the form,

$$
\mathrm{Hv}=\mathrm{aP}^{3}+\mathrm{bP}^{2}+\mathrm{cP}+\mathrm{d}
$$

Using a value of 20 for the Larson-Miller constant the following best fit equation with a $\mathrm{R}^{2}$ value of 0.9348 is obtained

$$
\mathrm{Hv}=0.1576 \mathrm{P}^{3}-12.345 \mathrm{P}^{2}+314.97 \mathrm{P}-2385.3
$$

The mean maximum and minimum hardness values calculated using equation $2 \mathrm{~b}$ are $247.2 \mathrm{Hv} 20$ and $208.4 \mathrm{Hv} 20$ which correspond to LMP values of 22.16 and 30.05 respectively.

Creep exposure tests. The results for Vickers hardness measurements on sections from unstressed areas in the heads of the fractured creep rupture test pieces are shown compared with the thermal exposure hardness data in Figure 4a. Although the data set is smaller (22 results compared with 62 in the case of the thermal exposure data set), the hardness values lie reasonably close to and follow a similar trend to those obtained for the thermally exposed tests. In addition, comparison of the two data sets show that once more the maximum and minimum hardness values occur at Larson-Miller parameter values of approximately 22 and 30 respectively. Regression analysis of the hardness data from the creep rupture specimen heads also gives a reasonably good fit with a third order polynomial in $\mathrm{P}$ with a $R^{2}$ value of 0.9422 being obtained, Table II.

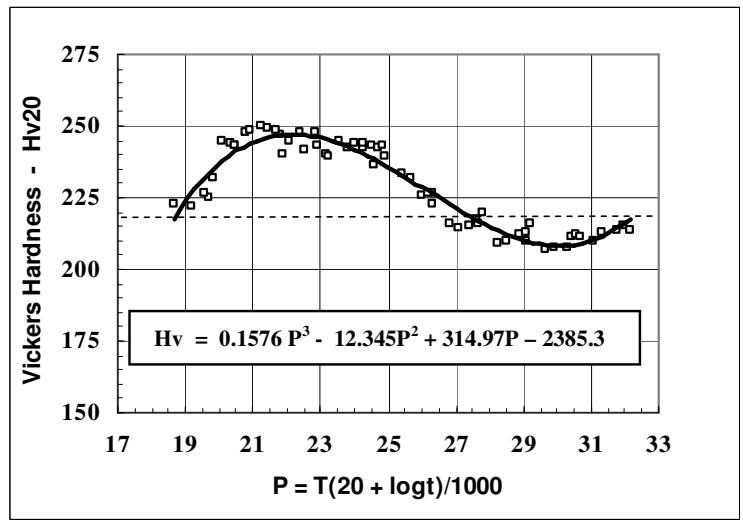

Figure 3. Hardness data for thermally exposed HA230 test coupons.

On the basis of these analyses and the relative closeness of the match between the hardness data sets shown in Figure 4a, it is considered that the hardness data from the thermal exposure tests and sections from the unstrained heads of the creep specimens can reasonably be pooled and the combined data analysed to produce a Master Hardness v Larson-Miller parametric plot for this alloy as shown in Figure 4b.

Regression analysis of the combined data indicates that use of a cubic polynomial to represent the data is once more valid resulting in a $R^{2}$ value of 0.9286 with the following Master Hardness $\mathrm{v}$ Larson-Miller equation representing variations in hardness on unstressed HA230 exposed for durations of up to 20,000 hours at temperatures in the range of $600^{\circ} \mathrm{C}$ to $1050^{\circ} \mathrm{C}$. 
Table II. Regression coefficients and least squares correlation values for thermally exposed and creep exposed HA230 hardness v Larson-Miller plots

\begin{tabular}{|c|c|c|c|c|c|}
\hline Exposure & \multicolumn{5}{|c|}{ Values of regression coefficients and $\mathrm{R}^{2}$ correlation values } \\
\hline Data & $\mathrm{a}$ & $\mathrm{b}$ & $\mathrm{c}$ & $\mathrm{d}$ & $\mathrm{R}^{2}$ \\
\hline Thermal Exposure & 0.1576 & -12.345 & 314.97 & -2385.3 & 0.9348 \\
\hline Creep Heads & 0.2218 & -17.089 & 431.0 & -3327.5 & 0.9422 \\
\hline Combined Data & 0.1581 & -12.355 & 314.57 & -2377.4 & 0.9286 \\
\hline
\end{tabular}
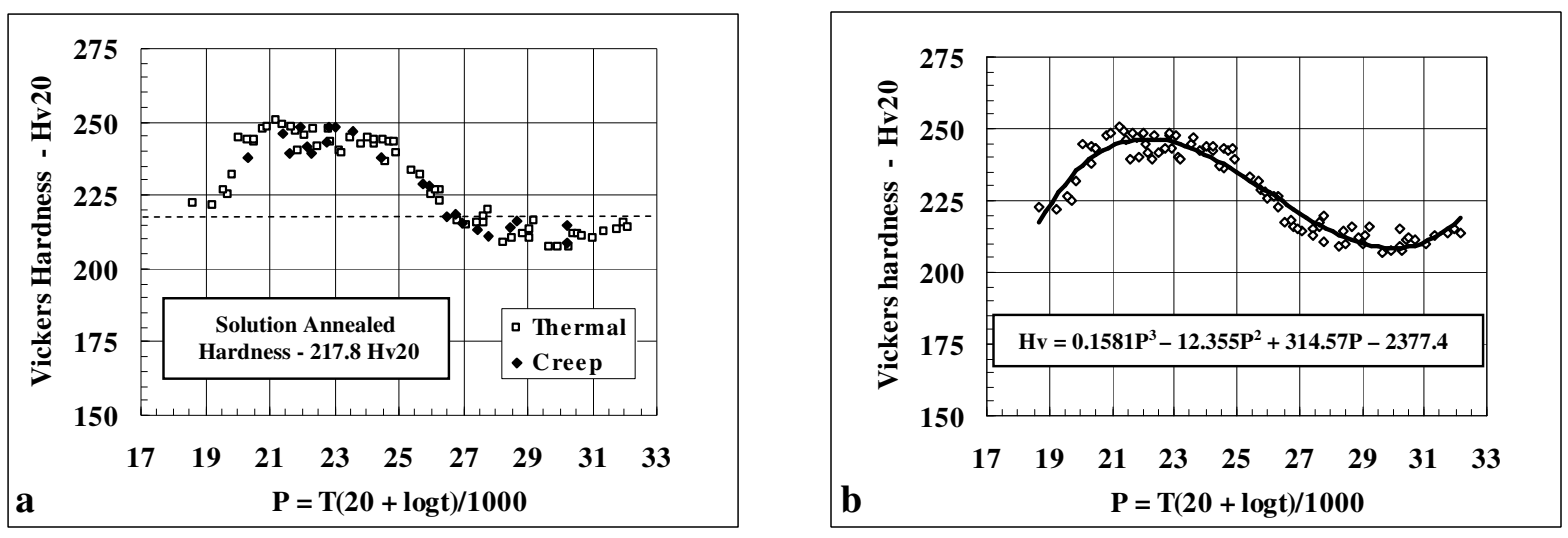

Figures 4a and 4b. Combined Thermal and Creep Head Hardness Data Plots for HA230.

$$
\mathrm{Hv}=0.1581 \mathrm{P}^{3}-12.355 \mathrm{P}^{2}+314.57 \mathrm{P}-2377.4
$$

Relationships of the type shown in Equation 3, derived from Master Hardness/Larson-Miller plots for HA230 enable hardness measurements made on ex-service combustion components manufactured from this alloy to be used for estimation of the average temperature experienced by these components for known periods of operation in service. This in turn can prove to be useful in estimation of the remaining service life of components manufactured from this alloy.

\section{Metallographic Studies}

Thermal exposure tests. Optical microscopy studies on the HA230 coupons thermally exposed for durations of up to 20,000 hours at temperatures in the range $600^{\circ} \mathrm{C}$ to $1050^{\circ} \mathrm{C}$ have revealed microstructural features which can be directly related to the changes in hardness already shown in Figures $2 \mathrm{a}$ and $b$. These observations indicate that evolution of the microstructure can be best described in terms of the effects of isothermal and isochronal exposure. For example, as shown in Figure 5, exposure for 1000 hours at $600^{\circ} \mathrm{C}, 650^{\circ} \mathrm{C}$ and $700^{\circ} \mathrm{C}$ results in precipitation of $\mathrm{M}_{23} \mathrm{C}_{6}$ type carbides on grain and original annealing twin boundaries. This, as evident from Figure $2 \mathrm{~b}$, is associated with corresponding increases in hardness of $12.35 \%, 14.96 \%$, and $13.73 \%$ compared with the original solution annealed condition hardness of 217.8 Hv20, with the peak hardness corresponding to an exposure temperature of $650^{\circ} \mathrm{C}$. Similar results were also observed for samples exposed for 500 hours over the same temperature range. Once more a hardness peak was observed at $650^{\circ} \mathrm{C}$ which in this case was $14.96 \%$ greater than that of the material in the original solution treated condition, Figure $2 b$.

A selection of micrographs illustrating the results of optical microscopy studies on the effects of exposures at temperatures in the range $750^{\circ} \mathrm{C}$ to $1050^{\circ} \mathrm{C}$ for durations of 1000 hours to 20000 hours on the microstructure of the HA230 coupons are shown in Figure 6.

The precipitation of $\mathrm{M}_{23} \mathrm{C}_{6}$ type carbides, on grain boundaries and annealing twins, following exposure for 1000 hours at $750^{\circ} \mathrm{C}$ is associated with the previously observed increase of $12.35 \%$ in the hardness of the alloy compared with the material in its original annealed condition, i.e. 244.7 Hv20 compared with $217.8 \mathrm{Hv} 20$. Further exposure at this temperature results in very gradual softening of the material with its hardness after 20,000 hours being reduced to $243.2 \mathrm{Hv} 20$, i.e. less than $1 \%$ lower than the value after exposure for 1000 hours at this temperature, Figure 2a. These changes are reflected in those observed in the microstructure with re-softening at $750^{\circ} \mathrm{C}$ being associated with progressive coarsening of $\mathrm{M}_{23} \mathrm{C}_{6}$ type carbides
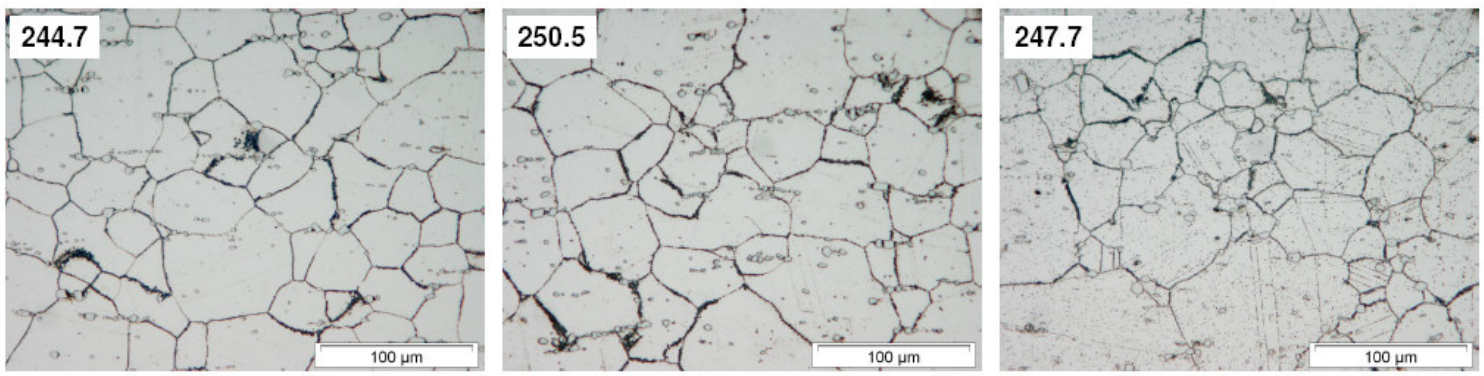

Figure 5. Effects of 1000 hours exposure at $600^{\circ} \mathrm{C}, 650^{\circ} \mathrm{C}$ and $700^{\circ} \mathrm{C}$ on the microstructure of unstressed HA230. 
followed by gradual re-solution of these precipitates in the microstructure, Figure 6. A similar pattern of microstructural evolution in the alloy has been observed in the case of isothermal exposure at $810^{\circ} \mathrm{C}$. However at this temperature, coarsening and subsequent re-solution of the precipitates occurred more rapidly with increasing exposure durations. This is consistent with the observed increased rate of re-softening of the alloy, as shown in Figure 2a, from an initial hardness of $239.2 \mathrm{Hv} 20$ after 1000 hours at $810^{\circ} \mathrm{C}$ to $223.0 \mathrm{Hv} 20$ after 20,000 hours exposure at the same temperature, i.e. a reduction of approximately $7 \%$ compared with that observed in the case of the material exposed for 20,000 hours at $750^{\circ} \mathrm{C}$. This hardness value was just over $2 \%$ greater than that of the material in the original solution annealed condition.

Exposure of the alloy for 1000 hours at $870^{\circ} \mathrm{C}$ revealed that while carbide precipitates were still present on the original grain boundaries there was no evidence of any precipitation on annealing twins in the material. In this case the measured hardness was $226.5 \mathrm{Hv} 20$, i.e. 4\% greater than that of the material in the original annealed condition. Further coarsening of the grain boundary precipitates was apparent for exposures of 15000 and 20000 hours at this temperature. After 3000 hours exposure at $870^{\circ} \mathrm{C}$ the hardness of the material had fallen to $216.1 \mathrm{Hv} 20$, i.e. 1\% lower than that of the material in its original solution annealed condition. In addition the evolution of the microstructure differed at this exposure temperature compared with that previously observed at $810^{\circ} \mathrm{C}$ and $750^{\circ} \mathrm{C}$.
Examination of material exposed at $930^{\circ} \mathrm{C}$ indicated that the microstructural changes were similar to those observed at $870^{\circ} \mathrm{C}$. However at $990^{\circ} \mathrm{C}$ and $1050^{\circ} \mathrm{C}$ precipitation at grain boundaries and within the grains became progressively much coarser for exposure durations of up to 10,000 hours, while at exposure durations of 15,000 and 20,000 hours additional large pool-like precipitates were observed in the microstructure. Micro-hardness measurements on these precipitates using a $50 \mathrm{~g}$ load gave an average value of $1190 \mathrm{Hv}$ compared with $180 \mathrm{Hv}$ for the matrix.

Similar observations have been reported by Jordan, et al [6] and Whittenberger [7] in studies of unstrained HA230 exposed for 10,000 hours at temperatures in the range $750^{\circ} \mathrm{C}$ to $1050^{\circ}$.

Creep tested HA230. Optical microscopy studies have also been carried out on microsections taken from the gauge lengths of selected creep rupture specimens, as well as from unstressed areas of the corresponding specimen heads, and the microstructures observed compared with those found in the solution annealed and thermally exposed material described above, Table III.

In all instances the fractures were intergranular with the creep damage in the form of cracking and grain boundary voiding being observed all along the gauge lengths and normal to the axial loading direction of the test pieces. In DKX, DLA and DLB the creep damage was mainly in the form of transverse

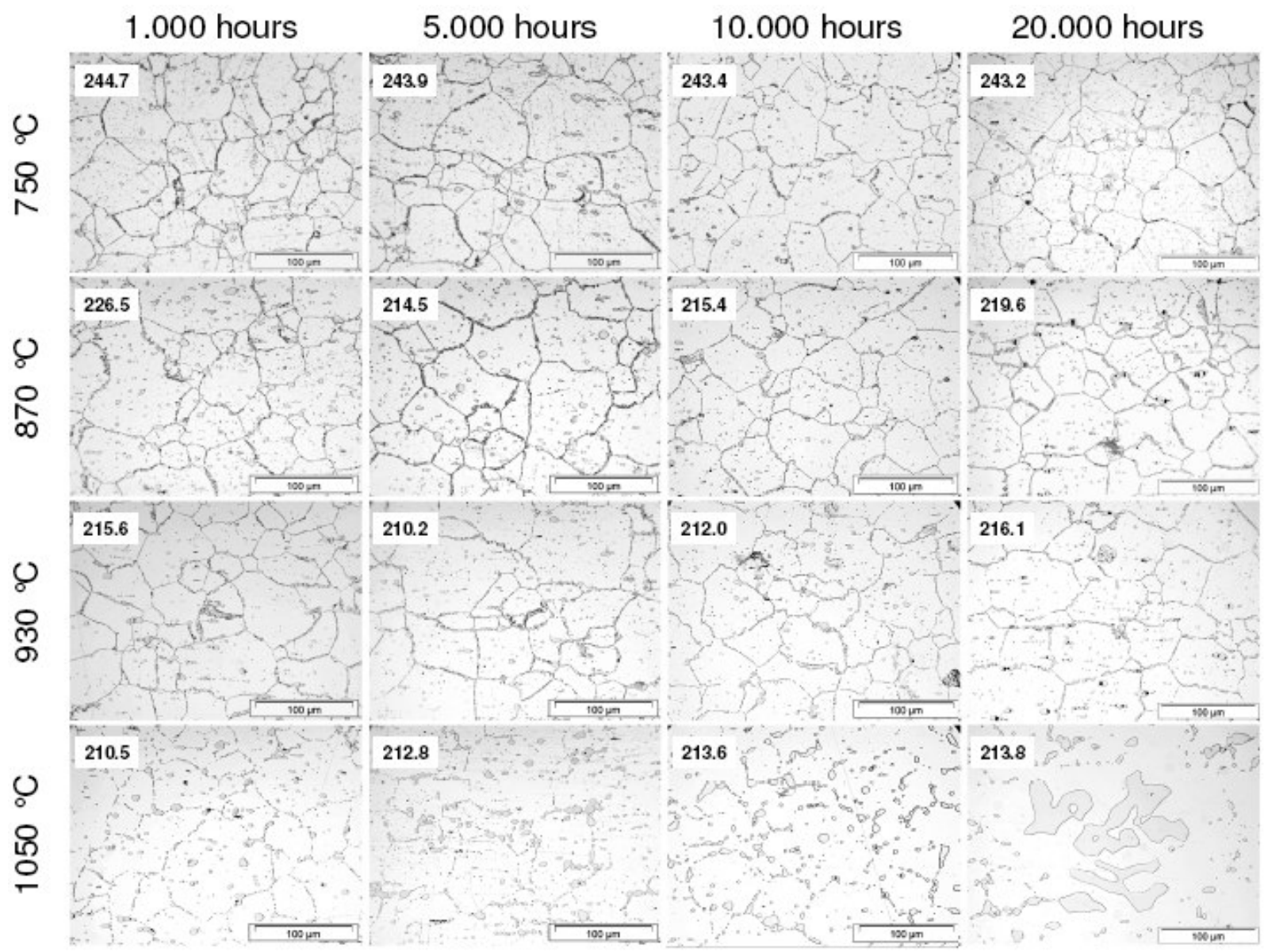

Figure 6. Effects of exposure at temperatures in the range $750^{\circ} \mathrm{C}$ to $1050^{\circ}$ on the microstructure of HA230 showing average Vickers hardness of each specimen (Hv20) 
intergranular cracks, while in specimens DLH, COD and COG, tested at the higher temperatures the damage was mainly in the form of large voids located on the grain boundaries normal to the applied stress, Figure 7.

Table III. Creep rupture test results on HA230

\begin{tabular}{|c|c|c|c|c|}
\hline Testpiece & $\begin{array}{c}\text { Temp. } \\
{ }^{\circ} \mathrm{C}\end{array}$ & $\begin{array}{c}\text { Rupture } \\
\text { Life } \\
\text { Hours }\end{array}$ & $\begin{array}{c}\text { Elongation } \\
\%\end{array}$ & $\begin{array}{c}\text { Larson- } \\
\text { Miller } \\
\text { Parameter }\end{array}$ \\
\hline DKX & 650 & 6577 & 20.7 & 21.98 \\
\hline DLA & 700 & 18160 & 17.2 & 23.60 \\
\hline DLB & 700 & 4995 & - & 23.05 \\
\hline DLH & 900 & 28776 & $\sim 35$ & 28.69 \\
\hline COD & 950 & 50874 & 66.7 & 30.21 \\
\hline COG & 1000 & 5366 & 70.8 & 30.20 \\
\hline
\end{tabular}

The general microstructure observed in the unstressed head and gauge length regions of test pieces DKX, DLA and DLB

consisted of chromium rich $\mathrm{M}_{23} \mathrm{C}_{6}$ type carbides precipitated at the grain boundaries and original annealing twin boundaries, together with large primary $\mathrm{M}_{6} \mathrm{C}$ carbides randomly distributed throughout the matrix. However, unlike the thermally exposed material, fine $\mathrm{M}_{23} \mathrm{C}_{6}$ precipitates were also found to be present in the creep strained gauge length regions of these test pieces. Both the grain and twin boundary precipitation appeared to be more pronounced in test-pieces DLA and DLB compared with that observed in DKX. This may be due to these tests having been carried out at $700^{\circ} \mathrm{C}$ compared with $650^{\circ} \mathrm{C}$ in the case of test-piece DKX and further supports the observations already made regarding the effects of temperature on the microstructures of the thermally exposed HA230 specimens.

The microstructures observed in test pieces DLH, COD and COG were totally different from those found in the gauge lengths of DKX, DLA and DLB. In the case of test DLH, which ruptured after 28,777 hours at $900^{\circ} \mathrm{C}$, the precipitation was almost continuous along the grain boundaries with coarse particles being also randomly present within the grains.

\section{Gauge length}

SE image
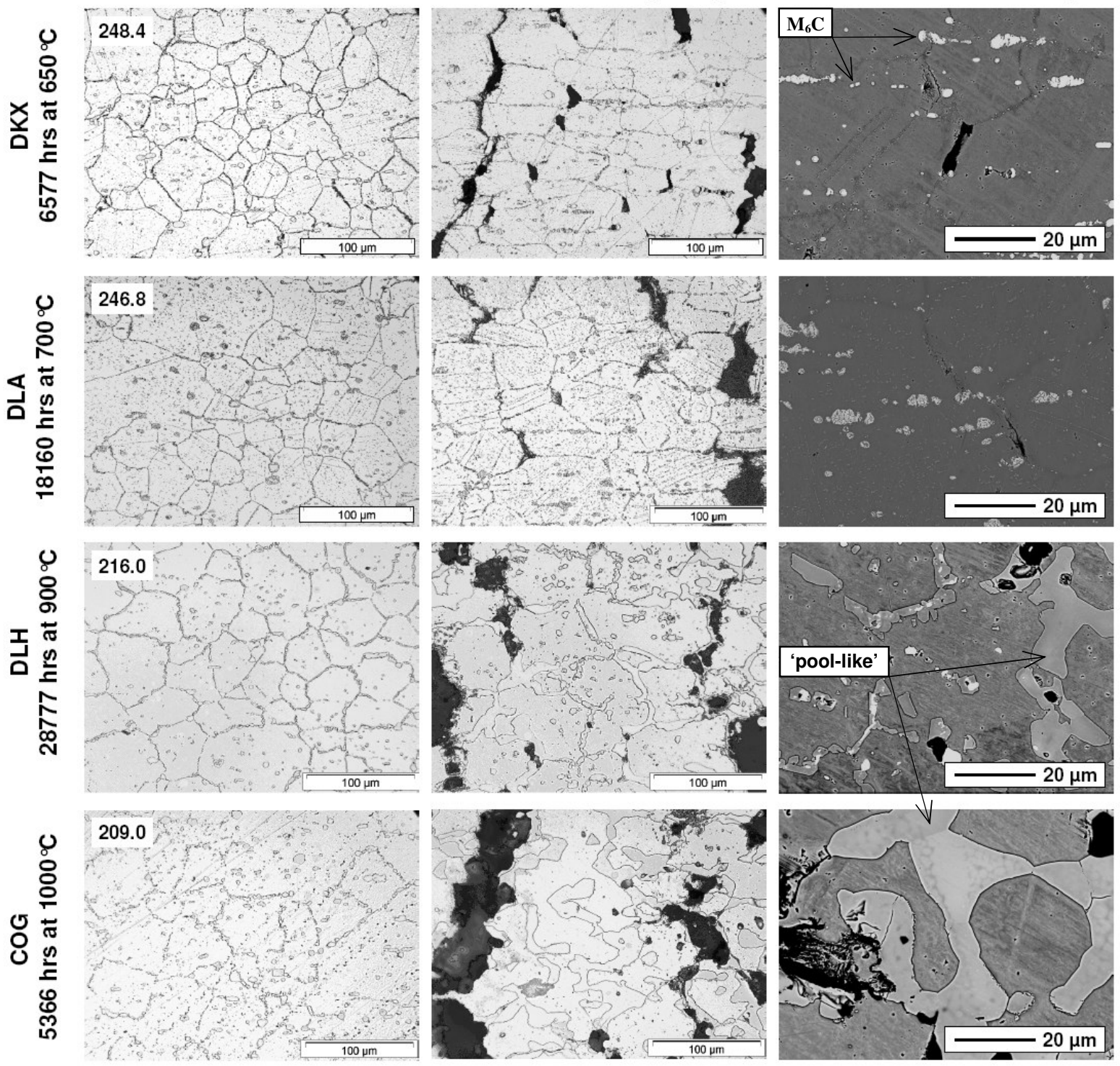

Figures 7. Microstructures of unstressed heads and gauge lengths in HA230 creep rupture test pieces. 
Whereas it was possible to differentiate between the primary and grain boundary carbide types in testpieces DKX, DLA and DLB, this was not possible optically in testpiece DLH since the particles were very similar in both size and shape. The microstructural differences were even more pronounced in $\mathrm{COG}$, which had fractured after 5366 hours at $1000^{\circ} \mathrm{C}$. In this case the grain boundary precipitation was continuous with no evidence of discrete particles being present. However in COD, which fractured after 50874 hours at $950^{\circ} \mathrm{C}$ and had an identical LMP value to COG, the precipitation appeared in the form of large almost isolated 'pools' with no obvious grain boundary structure being evident. Furthermore, while marked similarities were observed between the microstructures in the gauge lengths and unstressed head areas of DKX, DLA and DLB this was not the case for the higher temperature tests DLH, COD and COG. In these latter three tests coarse almost continuous precipitation was observed along the grain boundaries together with clear evidence of primary $\mathrm{M}_{6} \mathrm{C}$ particles remaining randomly dispersed throughout the respective matrices, Figure 7. These are similar to the microstructures observed in HA230 samples thermally exposed for durations greater than 10,000 hours at temperatures of $930^{\circ} \mathrm{C}, 990^{\circ} \mathrm{C}$ and $1050^{\circ} \mathrm{C}$.

However reverting back to highest temperature creep tests it is interesting to note that whereas the microstructure in the gauge length of DLH is a coarser version of that found in its unstrained head, pool-like precipitates similar to those observed in the gauge lengths of COD and COG have only been observed in material thermally exposed for 15,000 and 20,000 hours at $990^{\circ} \mathrm{C}$ and $1050^{\circ} \mathrm{C}$, Figures 5 and 7 . This suggests that the microstructural evolution observed in the creep tested material also occurs as a result of thermal exposure but at a much slower rate in the absence of plastic deformation due to creep.

\section{$\underline{\text { FEGSEM Studies }}$}

Previous SEM and EDX studies [8-10] have shown that carbide and other phases occurring in thermal and creep exposed high temperature materials can often be distinguished by their chemical signatures. Backscattered electron imaging and EDX mapping enable a qualitative assessment to be made regarding the distribution of specific elements and phases within the microstructure while EDX analysis techniques enable the compositions of both the matrix and individual phases to be determined quantitatively.

High resolution FEGSEM studies have been carried out using EDX mapping coupled with point and line scan analyses on the thermally exposed and creep tested HA230 test pieces described above and the results compared with the alloy in its original solution annealed and quenched condition.

Solution Annealed Condition. FEGSEM examination confirmed that the only precipitates present in the material in the original solution annealed and quenched condition were present in the form of stringers and as individual particles located at some of the grain boundaries. These were generally rounded in shape, with the majority ranging from approximately 1 to 10 microns in size. EDX analyses indicated that these precipitates, previously reported to be present by Klarstrom and others, were tungsten-rich and exhibited spectra consistent with primary $\mathrm{M}_{6} \mathrm{C}$ type carbides. The identity of this phase was confirmed by separate X-ray diffraction studies on the material, Figure 8.

Thermally Exposed Condition. In order to determine the effects of long-term thermal exposure on the microstructure of HA230 six specimens which had been exposed for 20,000 hours at temperatures in the range $750^{\circ} \mathrm{C}$ to $1050^{\circ} \mathrm{C}$ were analysed and the results compared with those previously obtained on the material in the solution annealed and quenched condition, Figures 8 and 9.

In the case of the $750^{\circ} \mathrm{C}$ exposed material in addition to the presence of primary $\mathrm{M}_{6} \mathrm{C}$, extensive precipitation of other particles were evident along grain and annealing twin boundaries in the microstructure. These were shown by EDX mapping and point analyses to be chromium rich and consistent with $\mathrm{M}_{23} \mathrm{C}_{6}$ type carbides which have previously been reported occurring in HA230 exposed at this temperature [4,6,7]. In addition to the presence of grain boundary precipitation, there was clear evidence of breakdown of the primary tungsten-rich $\mathrm{M}_{6} \mathrm{C}$ precipitates resulting from long-term exposure at $750^{\circ} \mathrm{C}$, Figure 9. Examination of the $810^{\circ} \mathrm{C}$ exposed material indicated microstructural changes similar to those found following
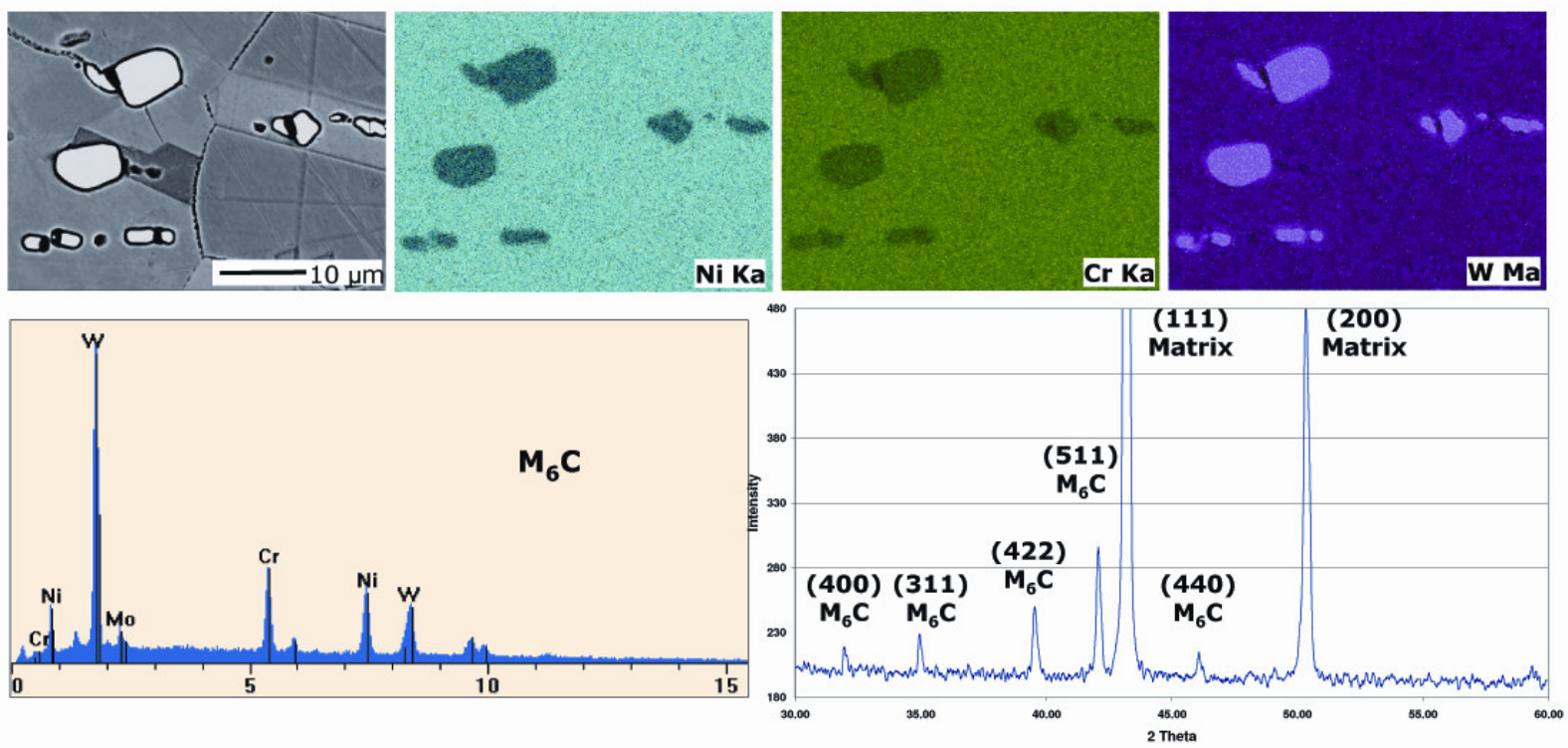

Figure 8. FEGSEM, EDX and XRD studies on HA230 in the original solution annealed and quenched condition. 
exposure at $750^{\circ} \mathrm{C}$ with clear evidence of breakdown of the $\mathrm{M}_{6} \mathrm{C}$ precipitates. However at this temperature the grain boundary precipitation was more continuous with evidence of some precipitates exhibiting differing back scattered electron contrasts in close contact with each other. The identities of these phases are currently being investigated.

The microstructure of the sample exposed at $870^{\circ} \mathrm{C}$ was significantly different from that found after exposure at $750^{\circ} \mathrm{C}$ and $810^{\circ} \mathrm{C}$. Tungsten rich $\mathrm{M}_{6} \mathrm{C}$ type precipitates, some of which were more than $10 \mu$ in size, were again present in the microstructure but at this exposure temperature there was no evidence of any breakdown of this phase. At this exposure temperature precipitation was almost continuous along the grain boundaries with many of the phases present existing in contact or embedded in one another. These precipitates tended to be irregular in shape and have complex chromium rich compositions. There was also evidence of some additional rodlike precipitates present within the grains. The microstructure following exposure at $930^{\circ} \mathrm{C}$ was generally similar to that found at $870^{\circ} \mathrm{C}$. However at this higher temperature both the tungsten and chromium rich precipitates were coarser and less irregularly shaped. In addition there was more evidence of complex conjoined precipitates in the microstructure.

In addition to a further coarsening of the phases already found in the $930^{\circ} \mathrm{C}$ sample, exposure at $990^{\circ} \mathrm{C}$ revealed the presence of large pool-like precipitates many of which were cracked and had enveloped tungsten rich particles. These precipitates, which are rich in chromium, tended to occur at grain boundaries in the microstructure and exhibited micro-hardnesses of approximately $1000 \mathrm{Hv}$ which possibly explains the cracking already referred to. At $1050^{\circ} \mathrm{C}$, the highest temperature of exposure investigated, the FEGSEM imaging revealed significant enlargement in the pool-like precipitates. Finally the microstructural features present following exposure at $1050^{\circ} \mathrm{C}$ were similar to those found at $990^{\circ} \mathrm{C}$.

Typical FEGSEM micrographs and EDX distribution maps for $\mathrm{Ni}, \mathrm{Cr}$, and $\mathrm{W}$, illustrating the points made above are shown in Figure 9.

Creep Exposed Condition. FEGSEM images and EDX distribution maps for nickel, chromium and tungsten are shown for sections from the gauge lengths of creep specimen DLH in Figure 10. These maps clearly show the networks of chromium rich grain boundary precipitates together with large tungsten rich primary $\mathrm{M}_{6} \mathrm{C}$ precipitates in addition to other unidentified tungsten containing particles at the grain boundaries. In addition pool-like precipitates similar in composition to those found in the thermally exposed material after 15000 hours at $990^{\circ} \mathrm{C}$ and $1050^{\circ} \mathrm{C}$ have been observed.

\section{0 hours}
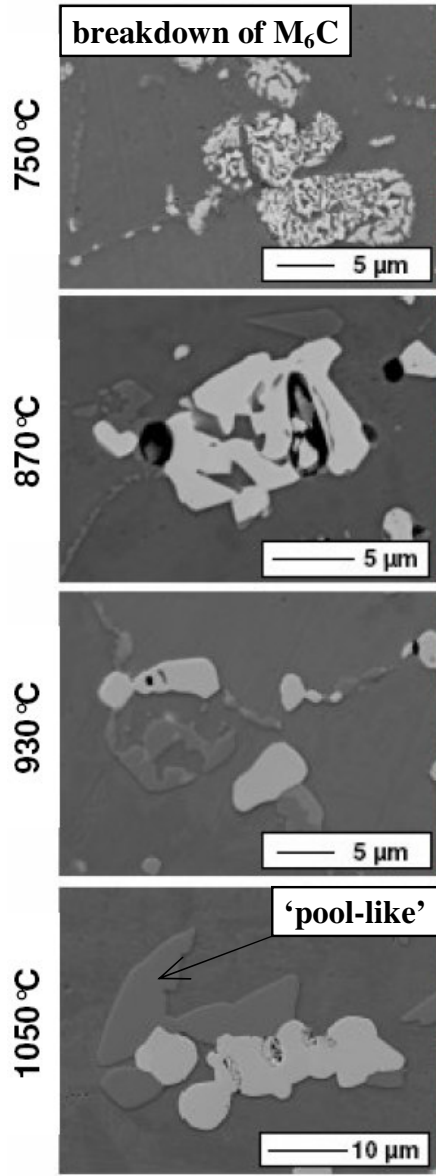

$\mathrm{Ni}$
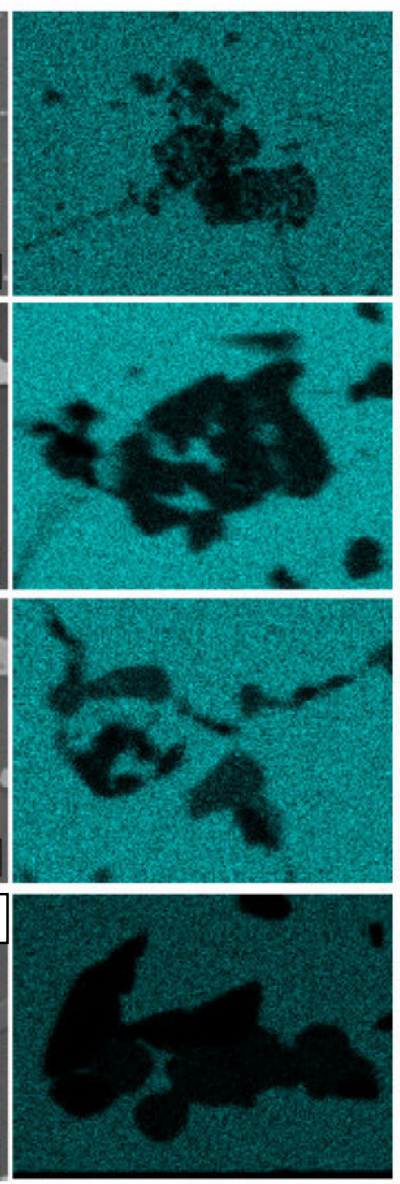

$\mathrm{Cr}$
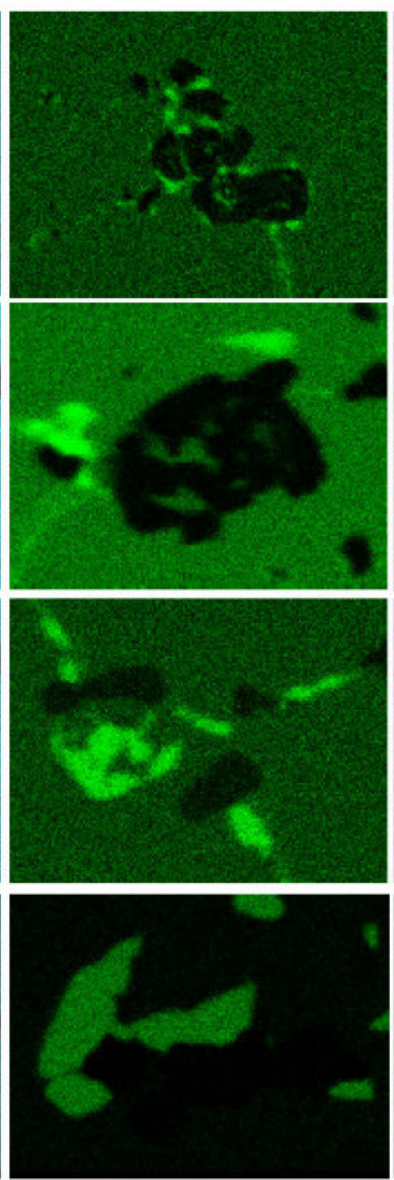

W
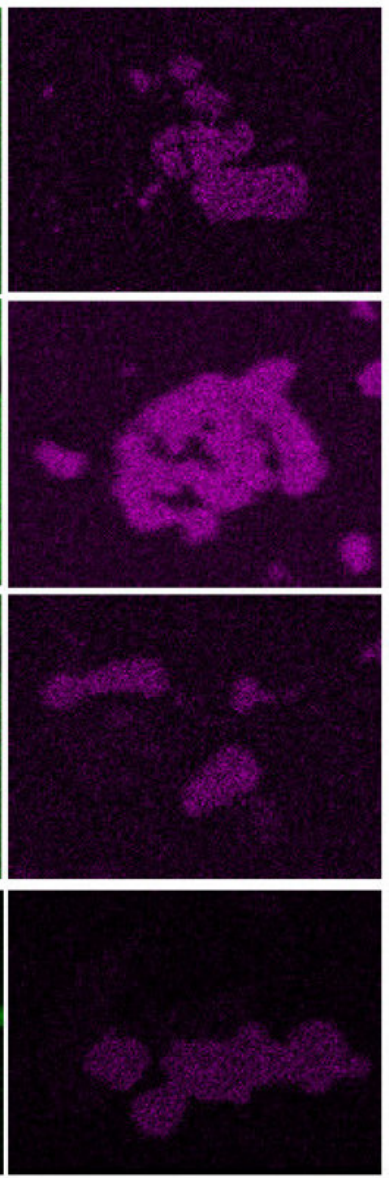

Figures 9. Typical FEGSEM micrographs and EDX element distribution maps for selected HA230 samples exposed for 20000 hours. 
Similar FEGSEM distribution maps for nickel, chromium, tungsten and molybdenum from the gauge length region of creep specimen COG are shown in Figure 11. These maps clearly show that in this case both grain boundary and individual precipitates in the microstructure are enriched in chromium, tungsten and molybdenum. Pool-like precipitates similar to those observed in the gauge length section of DLH have also been found in COG. In this case however the phase appears to be in continuous networks at the grain boundaries.

A comparison of the EDX point analyses data from the gauge lengths of creep specimens DLH and COG show that there are significant differences between the compositions of both the matrices and the precipitated phases in these samples. For example preliminary results indicate that while the molybdenum contents of the matrices are similar there are significant differences in their respective chromium, tungsten and nickel contents. In DHL both the chromium and tungsten contents are similar at $17.07 \%$ and $17.23 \%$ respectively, while in COG the corresponding values are $12.55 \%$ and $13.36 \%$. These are balanced by changes in the nickel content of the DHL matrix of $62.9 \%$ and 71.49 in the matrix of COG. It is also worth noting the differences in the types and composition of precipitates found in the gauge lengths of the DHL and COG creep specimens. In the former both $\mathrm{M}_{6} \mathrm{C}$ and $\mathrm{M}_{23} \mathrm{C}_{6}$ phases appear to be present with the latter in combination with another unidentified phase at the grain boundaries. In COG the situation differs with clear evidence of rounded, triangular and pool-like precipitation with variable compositions, none of which have so far been identified. No evidence of the primary $\mathrm{M}_{6} \mathrm{C}$ precipitate has been observed in the gauge length of this creep specimen.
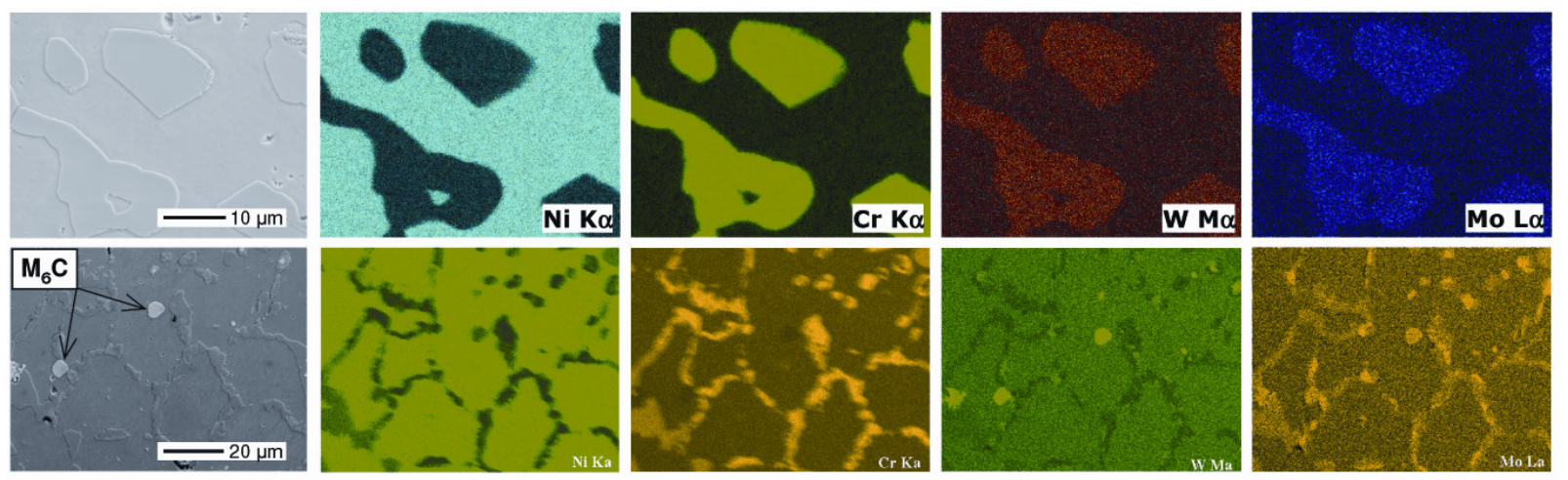

\begin{tabular}{|c|c|c|c|c|}
\hline EDX Analyses Of The Different Phases (Wt\%) - DLH - gauge length \\
\hline & $\mathrm{Ni}$ & $\mathrm{Cr}$ & $\mathrm{W}$ & Mo \\
\hline Matrix & 62.9 & 17.1 & 17.2 & 2.8 \\
\hline M $_{6}$ C & 16.0 & 10.9 & 67.9 & 5.2 \\
\hline 'pool-like' & 31.8 & 43.6 & 19.4 & 5.2 \\
\hline Cr-rich phase & 30.8 & 40.1 & 24.4 & 4.7 \\
\hline
\end{tabular}

Figure 10. FEGSEM and EDX images of carbides present in gauge length of creep test piece DLH (28776 hours at $\left.900^{\circ} \mathrm{C}\right)$.
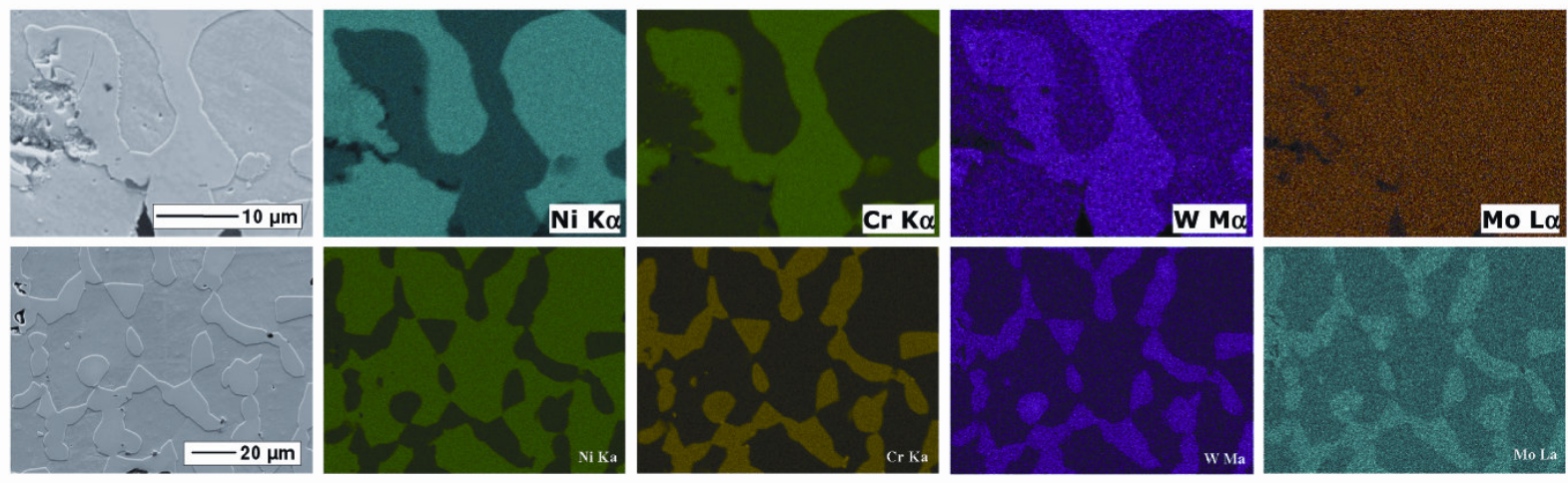

\begin{tabular}{|c|c|c|c|c|}
\hline \multicolumn{5}{|c|}{ EDX Analyses Of The Different Phases (Wt\%) - COG - gauge length } \\
\hline & $\mathrm{Ni}$ & $\mathrm{Cr}$ & $\mathbf{W}$ & Mo \\
\hline Ni-rich Matrix & 73.3 & 12.9 & 12.7 & 1.0 \\
\hline 'pool-like' & 31.9 & 41.4 & 22.9 & 3.8 \\
\hline
\end{tabular}

Figure 11. FEGSEM and EDX images of carbides present in gauge length of creep test piece COG (5366 hours at $1000^{\circ} \mathrm{C}$ ). 


\section{Conclusions}

The results to date have demonstrated that hardness data from thermal and creep exposure tests conducted on HA230 for up to 50,000 hours in the temperature range $600^{\circ} \mathrm{C}$ to $1050^{\circ} \mathrm{C}$ can be combined and analysed for the purposes of generating a master Hardness v Larson-Miller parametric plot which may be used for the purposes of estimating average in-service exposure temperatures for this alloy. A least squares regression analysis has shown that a cubic polynomial between hardness and the Larson-Miller parameter gives a good fit to these data with a best fit $R^{2}$ value of 0.9286 .

Optical microscopy and FEGSEM studies on thermally exposed HA230 have revealed microstructural factors which can be directly correlated with the observed changes in hardness due to thermal exposure over the range of temperature and durations investigated. The results have shown that the initial increases in hardness above that of the alloy in the as-received solution annealed condition are consistent with precipitation of $\mathrm{M}_{23} \mathrm{C}_{6}$ carbides at grain boundaries and original annealing twin boundaries within the grains. Subsequent exposure for longer durations and higher temperatures results in re-softening of the alloy. This is considered to be due to progressive $\mathrm{M}_{23} \mathrm{C}_{6}$ coarsening and the formation of other phases within the alloy. Current studies are aimed at evaluating and identifying the precipitation sequences due to long-term thermal exposure at temperatures up to $1050^{\circ} \mathrm{C}$ in this alloy.

Similar studies conducted on the heads and gauge length regions of creep tested $\mathrm{HA} 230$ have shown that at the lower test temperatures, viz., $650^{\circ} \mathrm{C}$ to $750^{\circ} \mathrm{C}$, the microstructures were similar to those observed in the thermally exposed material. However at test temperatures above this almost continuous precipitation occurs along grain boundaries together with coarse particles apparently randomly distributed within the grains. The effects of creep strain on the microstructure was most pronounced at the highest testing temperatures, viz., $950^{\circ} \mathrm{C}$ and $1000^{\circ} \mathrm{C}$, where significant changes were apparent in both the appearance and composition of precipitation both in the heads and gauge length regions of the creep test pieces. Once more changes in the microstructure in the heads of these test pieces was mirrored in the microstructures of the thermally exposed coupons exposed for 20,000 hours at temperatures $>900^{\circ} \mathrm{C}$.

\section{References}

1. Haynes International. HAYNES 230 Alloy Product Brochure, H-3000: www.haynesintl.com.

2. D.L. Klarstrom, "The Development of Haynes 230 Alloy," Corrosion, (1994), 407/1-407/12.

3. D.L. Klarstrom, "Heat treatment/Property Relationships for Solid-Solution Strengthened Heat Resisting Alloys". (Paper presented at the 1st International Conference on Heat Resistant Materials. Lake Geneva. 1991).

4. D.L. Klarstrom, "The Thermal Stability of a Ni-Cr-W-Mo Alloy". (Paper presented at the NACE Corrosion 94. Houston, TX, USA. 1994), Paper No. 407.

5. S.J. Matthews, Thermal Stability of Solid Solution Strengthened High Performance Alloys. (Baton Rouge, LA, USA. Superalloys: Metallurgy and Manufacture: Claiter's Publishing, 1976), 215-226.
6. C.E. Jordan, R.K. Raserfske, and A. Castagna, "Thermal Stability of High Temperature Structural Alloys, Long Term Stability of High Temperature Materials". (Paper presented at the Proceedings of TMS Annual Meeting. 1999), 55-67.

7. J.D. Whittenberger, "77 to $1200 \mathrm{~K}$ Tensile Properties of Several Wrought Superalloys after Long-term 1093K Heat Treatment in Air and Vacuum," Journal of Materials Engineering and Performance. 3(1)(1994), 91-103.

8. K.S. Vecchio, M.D. Fitzpatrick, and D.L. Klarstrom, "Influence of Subsolvus Thermomechanical Processing on the Low-Cycle Fatigue Properties of HAYNES 230 Alloy," Metallurgical and Materials Transactions A: Physical Metallurgy and Materials Science. 26(3)(1995), 673-689.

9. G.R. Marchant, G.M. McColvin, and A. Strang, "Materials for Advanced Power Engineering". (Paper presented at the $8^{\text {th }}$ Liege Conference. October 2006), 571-582.

10. J. Veverkova, A. Strang, G.R. Marchant, G.M. McColvin, and H.V. Atkinson, "Microstructural evolution in high temperature creep and thermally aged HA230". (Paper presented at the 7th International Charles Parson Turbine Conference. Glasgow. September 2007), 161-172.

\section{Acknowledgements}

The authors would like to thank their respective organizations for their support in this work and permission to publish this paper. The authors are also grateful to the COST538 consortium for facilitating the programme that this study forms part of. 